\title{
Hassan Melehy, «'Grand' richesse»: Du Bellay and Marot, a petrarchan navigation
}

\section{Filippo Fassina}

\section{Q OpenEdition}

1 Journals

\section{Edizione digitale}

URL: http://journals.openedition.org/studifrancesi/9819

DOI: $10.4000 /$ studifrancesi.9819

ISSN: 2421-5856

\section{Editore}

Rosenberg \& Sellier

\section{Edizione cartacea}

Data di pubblicazione: 1 octobre 2007

Paginazione: $425-426$

ISSN: 0039-2944

\section{Notizia bibliografica digitale}

Filippo Fassina, «Hassan Melehy, «'Grand" richesse»: Du Bellay and Marot, a petrarchan navigation», Studi Francesi [Online], 152 (LI | II) | 2007, online dal 30 novembre 2015, consultato il 09 janvier 2021. URL: http://journals.openedition.org/studifrancesi/9819; DOI: https://doi.org/10.4000/studifrancesi.9819

Questo documento è stato generato automaticamente il 9 janvier 2021.

\section{(c) (i) (9)}

Studi Francesi è distribuita con Licenza Creative Commons Attribuzione - Non commerciale - Non opere derivate 4.0 Internazionale. 


\title{
Hassan Melehy, “Grand' richesse»: Du Bellay and Marot, a petrarchan navigation
}

\author{
Filippo Fassina
}

\section{NOTIZIA}

HASSAN MELEHY, «'Grand’ richesse»: Du Bellay and Marot, a petrarchan navigation, «Bibliothèque d'Humanisme et Renaissance», LXVIII, 3 (2006), pp. 483-497.

1 Il presente studio analizza il rapporto intertestuale tra Marot e Du Bellay in relazione al comune modello petrarchesco. Lo studioso si concentra sulla canzone 323 dei Rerum vulgarium fragmenta (Standomi un giorno solo a la fenestra), tradotta da entrambi i petrarchisti, per dimostrare che il Songe di Du Bellay è a sua volta un calco letterale su Marot, benché tale modello sia contemporaneamente disprezzato ed elogiato rispettivamente nella Deffence e nell'olive. Per quanto riguarda la polemica tra i due autori, il saggio presenta come possibili motivazioni sia il contrasto tra Du Bellay e Sébillet (quest'ultimo, infatti, nel suo Art poetique propone come modello proprio Marot) sia la divergenza in materia religiosa tra il cattolico Du Bellay e il protestante Marot. Proprio partendo da questo elemento l'A. offre una serie di esempi che dimostrano il moltiplicarsi di interpretazioni di Petrarca in chiave protestante, specialmente nella corte di Ferrara. Anche il confronto testuale tra i tre componimenti in questione è studiato sotto l'aspetto dell'allegoria (Melehy ripropone una sua interpretazione basata sul concetto di allegoria legato all'idea di traduzione-imitazione proposto da Du Bellay nella Deffence). In questo caso si tratta di un'allegoria della storia della Chiesa con una prospettiva leggermente diversa a seconda della convinzione religiosa degli autori. In conclusione, Melehy afferma che l'imitatio operata da Du Bellay nei confronti di Marot è decisamente più ricca e complessa di un semplice rapporto di traduzione-mediazione di Petrarca, ma si situa all'interno del proposito centrale della Deffence, enrichir la langue, con l'aggiunta di un'implicazione religiosa di matrice 
protestante comune a tutti e tre i componimenti che permette di coniare i termini «reforming Petrarch»e «reforming imitation». 